\title{
A inovação organizacional por meio da Voz do consumidor e da Co-criação
}

The organizational innovation through Voice of Customer and Co-creation

CAMILLO, Maiara; Doutoranda em Design; UFSC

maiarag@gmail.com

SILVA, Ana Lúcia; Mestre em Design; UFSC

aannaluh.als@gmail.com

MERINO, Giselle S. A. D.; Doutora em Engenharia de Produção, UFSC

gisellemerino@gmail.com

\section{Resumo}

O cenário econômico mundial passou por diversas transformações ao longo dos anos. Desta forma as empresas tiveram que buscar diferenciais competitivos. Atualmente, uma das grandes preocupações das organizações é como se aproximar do cliente e usar de sua experiência para melhorar os produtos e serviços. Neste sentido, duas ferramentas vêm se destacando pela interação com o cliente: a Voz do consumidor e a Co-criação. Elas permitem captar os anseios, necessidades e desejos dos consumidores a fim de obter maior inovação organizacional. $O$ resultado desta abordagem contextualiza os avanços nos processos decorrentes do envolvimento das organizações com seus consumidores. Para atingir tal objetivo, apresenta-se uma pesquisa bibliográfica e a explanação de três diferentes casos onde houve a inserção das ferramentas VOC e Co-criação em organizações.

Palavras-chave: Voz do consumidor; Co-criação e Inovação.

\begin{abstract}
The global economic scenario has undergone several transformations over the years. In this way the companies had to seek competitive advantages. Currently, a major concern of organizations is how to approach the customer and use their experience to improve products and services. In this regard two tools have been highlighted by the interaction with the customer is the consumer Voice and Co-creation that let you capture the desires, needs and desires of consumers in order to achieve greater organizational innovation. As a result of this approach is expected to contextualize advances in the process of including the organizations with their consumers. To achieve this goal there will be a literature review and explanation of three different cases where there was the inclusion of VOC tools and co-creation in organizations.
\end{abstract}

Keywords: Voice of Customer; Co-creation and Innovation. 


\section{Introdução}

Os sistemas econômicos mundiais passaram por diversas fases e processos de mudança evolutiva na relação das trocas mercantis, sendo visível o surgimento e crescimento de novos desejos de consumo. Mesmo antes de determos o poder da moeda como instrumento de valoração, o consumidor já obtinha respostas à necessidade de consumo, mas ainda não fazia parte do centro das atenções (MATTIELLO, 2002).

Na definição de Ferreira (1999), consumidor é "aquele que compra para gastar em uso próprio", e cliente é "aquele que usa os serviços ou consome os produtos de determinada empresa ou profissional". Se observarmos a linguagem comercial, existe uma diferença entre ambos, sendo considerado consumidor aquele que efetivamente utiliza o produto e cliente é a pessoa física ou jurídica que adquire um produto objetivando a revenda direta ou a sua transformação também com fins comerciais.

Quando os consumidores passam a não mais consumir o excedente produtivo e as estratégias de vendas não conseguem alavancar as vendas, surge a preocupação em descobrir o que verdadeiramente o consumidor quer e/ou está predisposto a adquirir. Desta constatação, nos meados dos anos de 1950, nasce a fase do Marketing propriamente dita. A partir desse ponto, busca-se então averiguar as verdadeiras necessidades e desejos, procurando satisfazer o consumidor. Descobre-se, inclusive, que é ele quem determina a sobrevivência e o sucesso das empresas (MATTIELLO, 2002).

Segundo Cobra (1992), a partir da década de 80, essa descoberta propiciou a implantação de diversos programas voltados ao entendimento de consumo como a psicologia de consumo, manifestações de necessidades e desejos, entre outras, colocando o consumidor como o objetivo principal das empresas. Vale salientar de que no início era mais uma forma de discurso promovido por várias empresas do que realmente um objetivo a ser alcançado.

As empresas que se orientam para o cliente certamente conseguem informações precisas que posteriormente podem ser utilizadas para determinar diretrizes, sistematizando e organizando a voz do cliente para todos os envolvidos no processo.

Com vistas a essa temática, esse artigo tem como objetivo principal demonstrar o contexto em que podemos observar os avanços nos processos de inter-relação entre empresas e consumidor final no fenômeno de desenvolvimento de novos produtos.

Tem como objetivos secundários a discussão dos modelos adotados em três cases que são relatados a fim de compreender o envolvimento dos clientes nos processos.

\section{Materiais e Métodos}

A pesquisa realizada para este artigo tem natureza qualitativa. Explora-se a coleta de informações bibliográficas, pesquisas desenvolvidas por terceiros e estudos de caso específicos sobre o assunto. $O$ delineamento adotado para a pesquisa é descritivo-exploratório.

Esta pesquisa apresenta estudos de caso que, no conceito de Guedes (1997), diz respeito ao acompanhamento de uma situação delimitada. Gil (1996) considera o estudo de caso um conjunto de dados que detalha e retrata o processo social, em uma fase ou em sua totalidade, permitindo o esclarecimento das várias relações internas e suas configurações culturais no âmbito 
do indivíduo, instituição social e até mesmo da nação.

\section{A voz do consumidor}

A voz do consumidor, conceito do inglês Voice of customer (VOC), são todos os atributos que influenciam na percepção e avaliação do consumidor quanto a qualidade de um produto, sistema ou serviço (CARVALHO, 2001). Neste sentido a voz do consumidor é uma atividade, programa ou rotina das organizações que esperam alcançar mudanças em busca da satisfação do consumidor.

De acordo com Carvalho (2001) captar a voz do consumidor, consiste em uma tarefa de monitoramento continuo, não apenas pelas mudanças naturais de percepção decorrentes do tempo, mas também pelo alcance de padrões da concorrência que alavancam as exigências de desempenho do consumidor.

Para tal, faz-se necessário dar oportunidade e ouvidos às indagações, reclamações, sugestões e desejos dos clientes, pois eles detêm a sabedoria sobre suas próprias necessidades. A voz do consumidor deve soar como um termômetro qualitativo e de satisfação (MATTIELLO, 2002). As empresas devem estar preparadas para lidar com estes dados e atentos às mudanças que podem ser desencadeadas deste processo. Aproveitar as competências do consumidor exige da organização um engajamento continuo e abertura para um diálogo ativo e claro (PRAHALAD e RAMASWANY, 2000).

Este processo de entender o cliente e dar voz a ele traz consigo vantagens competitivas para as organizações, além de capacitar e direcionar a visão da organização para o cliente. Junior e Carvalho (2003) ressaltam que as empresas que forem capazes de aproveitar o capital intelectual, tanto da força de trabalho interna como dos clientes, transformando em competências, terão maior chance de obter sucesso no cenário competitivo.

Katz (2004) lista os benefícios da adoção do VOC nas organizações:

- Mostra uma compreensão detalhada dos requisitos do cliente;

- É uma linguagem comum para equipe envolvida;

- É uma contribuição essencial na definição das especificações de design apropriadas para o desenvolvimento de produtos e serviços e;

- É um trampolim para inovação.

O processo de VOC gera um entendimento entre empresa e cliente, passando a ser uma maneira de integração de conceitos. Segundo Ryengen (2008) os consumidores podem fornecer informações confiáveis e diretas sobre situações e experiências as quais estejam familiarizados, de forma que é possível vê-los articular sobre os problemas e necessidades. Essas informações, uma vez de posse da organização, indicam mudanças em projetos já em andamento ou até mesmo direcionam a criação de novos projetos.

Os clientes podem interagir com empresas em vários estágios, desde a ideia inicial para o projeto até a entrega final do produto ou serviço, tornando este processo interativo. $O$ cerne 
desta interatividade é a proposição de que o cliente se torna um co-criador de valor, no qual por meio da abordagem é captada a voz do consumidor (RYENGEN, 2008).

\section{A co-criação}

A co-criação é um dos termos que emergiu para designar diferentes formas de participação dos consumidores em um cenário em que as fronteiras das empresas estão fragmentadas e os indivíduos se conectam em rede.

De acordo com Ramaswamy (2009), co-criação é um processo que visa a construção de um valor conjuntamente e que deve alcançar interesses mútuos. No processo de co-criação, o individuo não está sozinho, ele partilha das suas opiniões e essa é somada com a opinião dos demais envolvidos. Todos se propõem a transformar o elemento foco do qual estão discutindo. Neste sentido, as experiências somadas elencam pontos estratégicos para a empresa, primitindo o desenvolvimento de produtos, sistemas e serviços pautados na colaboração com clientes, gerentes, funcionários e stakeholders (RAMASWAMY, 2009).

Sendo assim, a co-criação vai além do processo de troca de experiências, das interações mutuas e do diálogo, ela na verdade permite uma avaliação fiel do risco e recompensa das ações, baseada na experiência multifacetada do ser humano (RAMASWAMY, 2009).

Para Leavy (2012), a co-criação pode ser aplicada a qualquer empresa, sendo ela grande ou pequena, cujos clientes tenham experiências a descrever. Desta forma o envolvimento dos usuários pode se dar de diferentes maneiras, desde encontros presenciais com poucos usuários até interações sociais via web envolvendo milhares de pessoas.

\section{A importância para a inovação organizacional}

A atual complexidade das ofertas, com grande variedade de produtos e serviços, nem sempre resulta em melhores experiências de consumo (PRAHALAD, RAMASWAMY, 2000). As empresas, que já não garantem sua lucratividade por meio de velocidade, qualidade e menores custos, precisam encontrar uma nova forma de valor por meio da criatividade e inovação.

A inovação é apontada como a principal fonte de vantagem competitiva das empresas. Na indústria ela produz como resultados o lançamento de novos produtos ou processos produtivos mais eficientes. A inovação é um processo muitas vezes confuso, algo difícil de se administrar, envolvendo várias pessoas, opiniões e desejos. Kanter, Kao e Wiersema (1998), ao abordar a inovação, registram que existe uma tendência ao romantismo quando se acredita que é sinônimo de intuição e inspiração. Na maioria das vezes a inovação em produtos ocorre nas extremidades e não no centro das organizações, ou seja, as ideias mais inovadoras surgem dos próprios usuários do produto.

Para Kanter, Kao e Wiersema (1998), uma das características das empresas inovadoras está em saber ouvir seus clientes, isto significa que a organização precisa ter humildade. Não dar ouvidos é uma inimiga mortal à inovação, paralisa a vontade de aprender e inovar. Deve-se lembrar que os anseios e desejos do consumidor tendem a ser refletidos nos projetos.

$\mathrm{Na}$ opinião de Shapiro (1994), o futuro terá como principal característica os relacionamentos em todas as áreas de negócios. O segredo estará em descobrir do consumidor 
quais os benefícios que ele mais valoriza e então passar a usá-los como diferenciais competitivos. Isso mostra como é importante a interação com os clientes no desenvolvimento de novos produtos. Os usuários podem direcionar o desenvolvimento do que eles querem, participando do processo de inovação da empresa.

Assim surge o conceito de co-criação, com a participação do cliente no processo de produção, interagindo com a empresa na busca da criação de valor (PRAHALAD, RAMASWAMY, 2000). Os consumidores, que no passado eram passivos, estão cada vez mais engajados no processo de criação de valor. A facilidade de acesso às ferramentas necessárias para a colaboração e co-criação, como, por exemplo, a Internet, podem possibilitar um canal aberto, proporcionando ao cliente um papel verdadeiro no desenvolvimento de novos produtos e serviços.

Os consumidores ativos, buscam produtos e experiências melhores. A co-criação torna-se fundamental para as empresas que desejam criar valor e repassá-lo aos seus clientes, mas elas deverão modificar alguns de seus processos internos, um custo pequeno se comparado aos benefícios de contar com a colaboração de seus clientes.

\section{Cases de organizações que realizam voc/co-criação}

\subsection{Nike + training}

A Nike é um exemplo de organização que utilizou da co-criação se aproximando do cliente para aprimorar seus produtos. Jay Lee, diretor de produtos sênior do Nike+, definiu que o objetivo do aplicativo é ser um personal trainer de bolso. Ele será capaz de auxiliar o usuário a atingir seus objetivos de exercícios físicos (CAPUTO, 2016). A colaboração ocorre desde o cadastro, no entanto, no começo, todos os usuários terão uma experiência parecida. Mas no decorrer do uso, o cliente continuamente adiciona informações e feedbaks de seus treinos, fazendo o aplicativo se moldar à sua personalidade de maneira mais pessoal. Isso possibilita, por exemplo, a indicação de treinos personalizados.

Outros recursos do aplicativo são disponibilizados para promover o envolvimento do usuário. São exemplos desses recursos a possibilidade de escolher uma seleção de musicas para ouvir durante o treino. Assim como uma integração com outros aplicativos, promovendo interação entre usuários.

Fica visível a VOC em respostas da marca nas atualizações do aplicativo. A versão 5.8.0, por exemplo, vem acompanhada da seguinte expressão: "Você pediu e nós ouvimos!" (APP STORE APPLE, 2017). Isso demonstra que correções no produto foram feitas periodicamente para adequações às necessidades dos clientes. Essas preocupações em atender às solicitações dos usuários resultam em uma avaliação bastante positiva, o aplicativo está com uma pontuação de 4.9, em uma escala que vai até 5 (APP STORE APPLE, 2017). 
Figura 1: comunicação de treinos personalizados

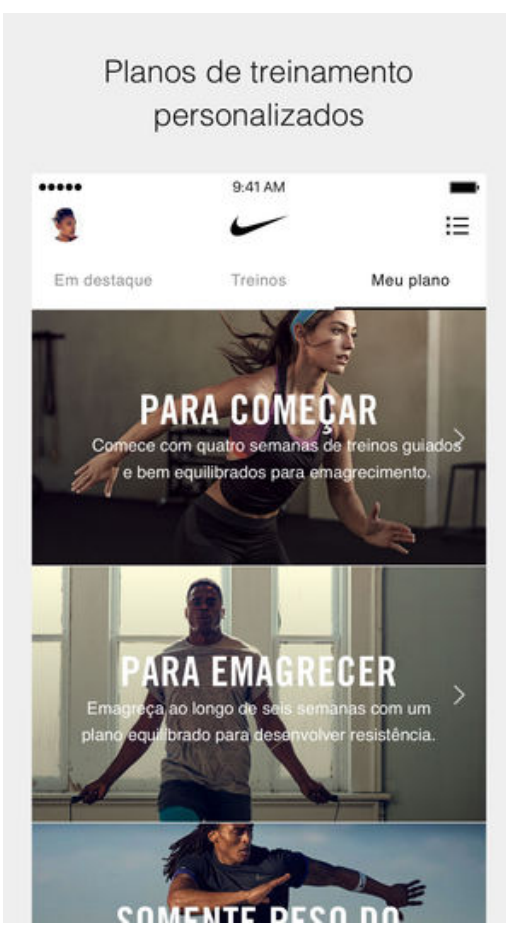

Fonte: App Store Apple (2017)
Figura 2: comunicação de recomendações diárias

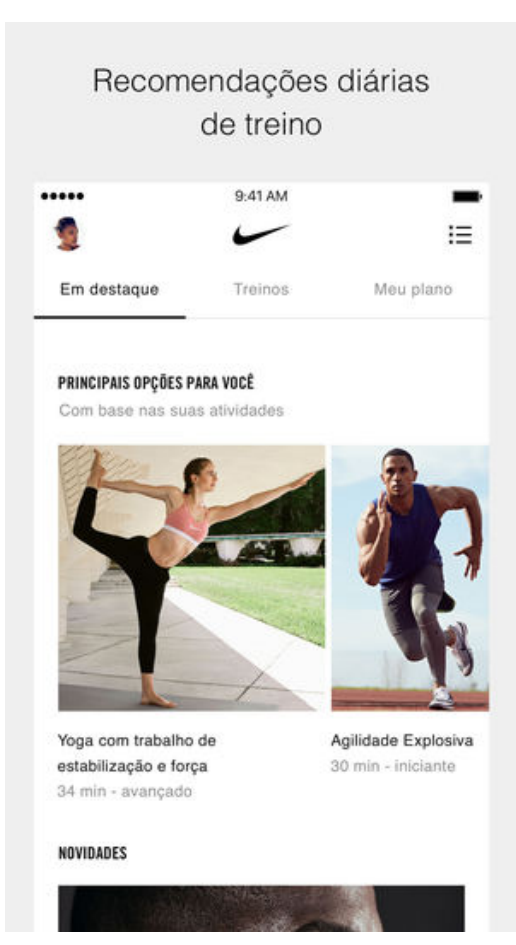

Fonte: App Store Apple (2017)
Figura 3: comunicação de treinos inspirados nos atletas

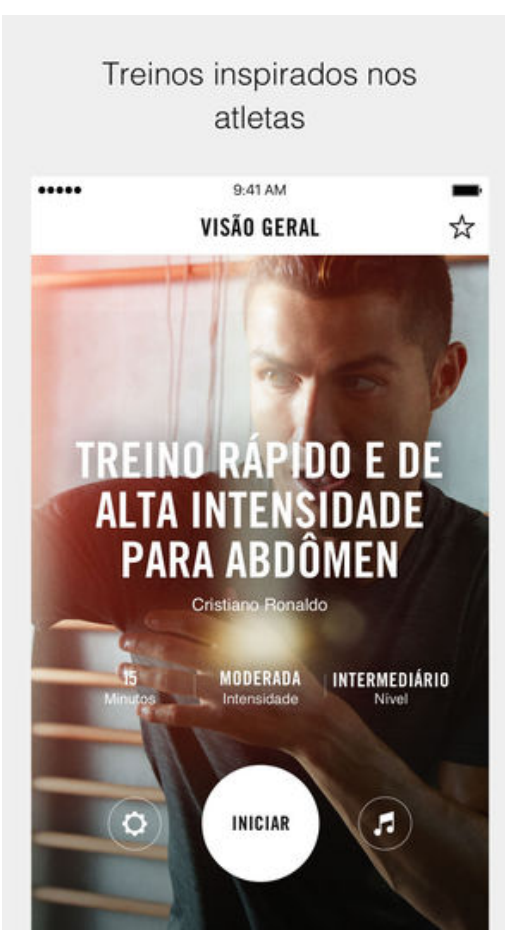

Fonte: App Store Apple (2017)

O aplicativo Nike + training é um canal de engajamento de cientes que gera benefícios para a empresa, como o conhecimento mais direto sobre o comportamento, hábitos e as preferências do seu consumidor. A participação ativa do usuário gera novas ideias mais rapidamente e diminui os riscos e custos em relação ao processo comum de desenvolvimento. Desta forma, para a Nike, o produto deixou de ser o ponto final de consumo e passou a ser o início e veículo de toda a experiência (LEAVY, 2012).

Isso corrobora com Ramaswamy e Gouillart (2010) quando relatam que o principal valor da co-criação é engajar as pessoas a criar valor juntas por meio de suas experiências. $O$ aplicativo desenvolvido pela Nike apresenta um canal de envolvimento com seus clientes, dando a eles a possibilidade de compartilharem suas experiências, acarretando em inovação ao produto.

\subsection{Fiat Mio}

A Fiat buscou co-criar com seus consumidores no projeto do Fiat Mio. A montadora convidou as pessoas para participarem da idealização do carro do futuro FCC III, o terceiro Fiat Concept Car a ser criado no Centro Estilo Fiat Brasil e que foi apresentado no Salão do Automóvel em outubro de 2010, em São Paulo (MAZINI et al., 2011).

Mazini et al (2011) relata que a colaboração foi aberta por meio de uma plataforma montada na internet para esse fim (fiatmio.cc) aos consumidores, formadores de opinião, especialistas, acadêmicos, para que contribuíssem com todos os tipos de ideias, técnicas ou não. Coube a Fiat organizar um processo de aproveitamento e solução para cada tema proposto pelos 
internautas. As discussões foram avaliadas e, com base em estudos de viabilidade técnica, transformadas em um componente do automóvel pelos engenheiros e designers.

O exemplo do projeto do Fiat Mio gerou uma experiência de envolvimento do usuário com a empresa Fiat que foi fundamental para o sucesso do projeto. Alguns elementos inovadores posteriormente foram repassados para a concepção dos carros comerciais. Sabe-se que muita das tecnologias, teste de novos conceitos e novos materiais que são aplicados em carros de produção em série vem das aplicações feitas em carros conceito. Estes representam o futuro do automóvel em relação a design, engenharia, tecnologia e usabilidade, entre outras características (MAZINI et al., 2011).

Além das inovações no produto, as quais a empresa utilizará para desenvolvimentos futuros, Mazini et al (2011) descreve outro resultado observado, a redução no tempo de desenvolvimento. Um projeto de um automóvel normalmente leva três anos para ir ao mercado, mas neste caso ficou pronto em 18 meses. 0 projeto também originou uma plataforma de relacionamento com o consumidor que pode ser utilizada não só para futuras pesquisas de mercado e tendências da indústria, mas também na identificação de mudanças referentes à opinião desse consumidor.

Figura 4: Logo da campanha Fiat Mio

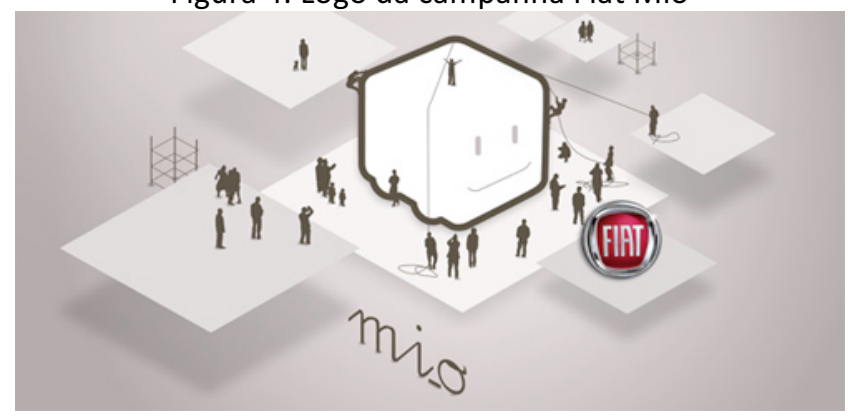

Fonte: Fiat (2015)
Figura 5: Projeto final Fiat Mio

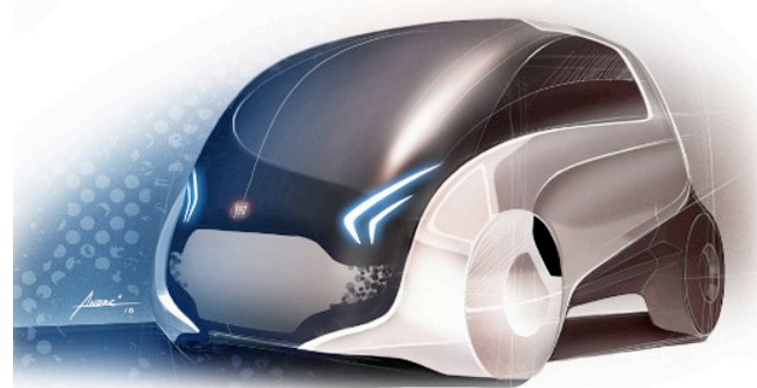

Fonte: Fiat (2015)

A Fiat acredita que o conhecimento gerado neste projeto deve ser propagado sem restrições, podendo ser utilizado por simples usuários ou até mesmo engenheiros e outros fabricantes de veículos.

\subsection{Tigre}

A Tigre é uma organização que sempre foi reconhecida por sua produção de tubos e conexões. Nos últimos anos teve um interesse em se aproximar do cliente e compreender o que os usuários dos produtos tinham a dizer sobre as linhas de produtos. Este interesse teve como objetivo identificar as necessidades e desejos de melhoria dos clientes.

A organização implantou o processo de VOC para a equipe de assistência técnica. Esses engenheiros aproveitariam suas visitas à obras e a construtoras para questionar sobre ideias relacionadas ao seu produto. $\mathrm{O}$ publico alvo deste processo eram pedreiros, mestres de obras, instaladores e projetistas. Estes relatos eram gravados por meio de vídeos com o celular e/ou registrados em fotos. Os usuários relatavam suas necessidades, contavam do dia-a-dia das obras e 
como a organização poderia melhorar seu produto.

A fim de incentivar a participação dos colaboradores Tigre na coleta da VOC, a organização se propôs a premiar os colaboradores que tivessem o relato dos clientes transformados em ações transformadoras aplicadas.

Figura 6: Coleta da Voz do consumidor.

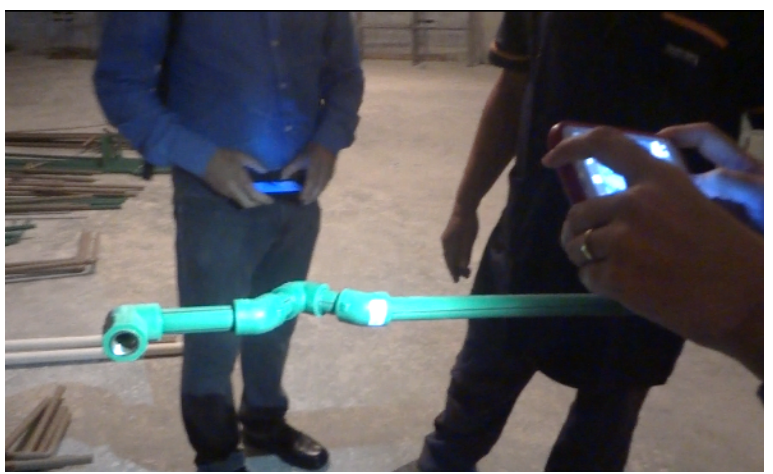

Fonte: as autoras (2015)

Esse processo teste foi observado durante os anos de 2013 e 2014. Neste período recebeu mais de 200 relatos de VOC, dos quais três viraram efetivamente produtos novos ou melhorias em produtos existentes. Além disso a organização conseguiu estabelecer um canal direto de colaboração com seus clientes e pôde compreender o dia-a-dia, as dificuldades e necessidades enfrentadas por eles.

\section{Discussão}

Nos três casos relatados, pode-se observar diferentes objetivos em se estabelecer a cocriação e a VOC. Porém foi comum o processo intencionando a aproximação do cliente, a elaboração de meios de coletar e armazenar as informações, assim como interpretar as contribuições para a geração de inovação.

A Nike, com seu aplicativo Nike+ training, direcionou seu trabalho de co-criação e VOC para atender as necessidades de um grupo de consumidores que buscam se exercitar de maneira autônoma. O uso constante do aplicativo pelo usuário, o alimentando de dados, aprimorava o produto na busca da personalização para cada cliente em sua especificidade. Ouvir os relatos sobre queixas também auxiliou os programadores para trabalharem em atualizações mais assertivas, acarretando posteriormente em uma excelente avaliação pelo cliente.

No caso da Fiat, a proposta era inserir o consumidor como agente idealizador em uma proposta de carro do futuro. Essa co-criação fez ele pensar de que forma suas necessidades do dia-a-dia poderiam ser satisfeitas em um carro de verdade. O carro conceito resultante do processo teve uma economia de tempo em sua concepção e foi exposto no salão do automóvel em 2010, significando a materialização de muitas ideias. Uma vez que se constrói o conhecimento sobre o cliente, abre-se a possibilidade de geração de inúmeros outras possibilidades de aplicação em projetos originais e inovadores.

No case da Tigre, a organização antes de co-criar com o cliente, quis ouvi-lo. Desta forma, 
coletou diversos depoimentos demostrando a interação dos usuários com os produtos, suas dificuldades e desejos de mudança. Este material fez com que a empresa refletisse sobre a sua postura adotada frente aos clientes e como, por meio de seus produtos e serviços, seria possível satisfazer os consumidores. Caracterizar o cliente é uma tarefa árdua que exige um conhecimento em torno do contexto vivido, o cenário económico e as condições que expõe este usuário a interagir com o produto. $O$ processo utilizado poderia ser mais bem explorado colocando mais funcionários como coletores de VOC, não somente os engenheiros da assistência técnica, como neste caso.

\section{Conclusões}

A inovação dentro da organização é capaz de agregar valor aos produtos e serviços diferenciando esta empresa das demais. Agregar valor é o que atualmente muitas empresas buscam e que pode ser alcançado se modelado juntamente com o cliente.

A voz do consumidor é a percepção do cliente sobre determinado produto ou serviço, sendo elencado em forma de atributos que possibilitam a satisfação de suas necessidades e desejos em relação aos itens. Este processo de ouvir o que o cliente tem para dizer permite com que as empresas captem os anseios de seus consumidores e possam aprender por meio de suas experiências.

A co-criação é a troca de experiências entre consumidores e empresas, os quais buscam construir o valor que esperam de maneira conjunta. Esta ferramenta auxilia as empresas a criar novas experiências com produtos e serviços pautadas na colaboração e discussão dos próprios envolvidos. Para estas organizações, a inovação é alcançada com o conceito da colaboração na qual o desenvolvimento passa a ser com o cliente e não sendo o cliente o ponto final do desenvolvimento, ele é ativo em todo o processo.

Esses processos buscam a inovações e trazem consigo o acesso a novos mercados, um aumento de receita, a realização de novas parcerias e o reconhecimento e aumento de suas marcas. A orientação para o cliente e a participação ativa deles no processo endossa a preocupação das organizações com seus usuários e assim demonstra o crescimento do conhecimento das empresas sobre eles.

\section{Referências}

APP STORE APPLE. Aplicativo Nike + training. Disponível em $<$ https://itunes.apple.com/br/app/nike-training-club/id301521403> Acesso em 20 de dezembro de 2017.

CAPUTO, Victor. Nike quer ser seu personal trainer com nova versão de app. Revista EXAME. Edição digital. 2016. Disponível em <https://exame.abril.com.br/tecnologia/nike-quer-ser-seupersonal-trainer-com-nova-versao-de-app/> Acesso em 13 de março de 2017.

CARVALHO, M. M. Qualidade em Projetos. in: AMATO. Manufatura Classe Mundial. São Paulo: Atlas, 2001.

COBRA, M. Administração de Marketing. 2. ed. - São Paulo: Atlas, 1992. 
FERREIRA, A. B. de H. Novo Aurélio Século XXI: O Dicionário da Língua Portuguesa. 3. ed. - Rio de Janeiro: Nova Fronteira, 1999.

FIAT. Fiat Mio <http://www.fiat.com.br> acesso em 27 de maio de 2015.

GIL, A. C. Métodos e técnicas de pesquisa social. 4 ed. São Paulo, Atlas, 1996.

GUEDES, E. M. Curso de Metodologia Científica. Curitiba: HD Livros, 1997.

JUNIOR, A.T.C. e CARVALHO, M.M. Obtenção da Voz do Consumidor: estudo de caso em um Hotel Ecológico. Revista Produção v. 13 n. 3. 2003.

KANTER, R. M.; KAO, J.; WIERSEMA, F. Inovação: Pensamento inovador na 3M, Dupont, GE, Pfizer e Rubbermaid. São Paulo: Negócio Editora, 1998.

KATZ, G. The Voice of the Customer, The PDMA Toolbook for New Product Development, John Wiley \& Sons. 2004.

LEAVY, Brian. Collaborative innovation as the new imperative - design thinking, value cocreation and the power of "pull". Strategy \& Leadership, Vol. 40 Iss 2 pp. 25 - 34. 2012.

MATTIELLO, N.V. Proposta de inclusão do consumidor como agente participativo no processo de desenvolvimento de novos produtos alimentícios. Dissertação de Mestrado. Universidade federal de Santa Catarina. Florianópolis. 2002.

MAZINI, Sergio Ricardo; JUNIOR, José Alcides Gobbo; JUGEND, Daniel. Inovação aberta e envolvimento de usuários no desenvolvimento de novos produtos: estudo de caso em projeto do setor automobilístico. 8 Congresso Brasileiro de Gestão e Desenvolvimento de Produto. Porto Alegre. 2011.

PRADO, D.D. Valor criado pelo cliente: Proposta de uma estratégia de design de ambientes virtuais de co-criação. Escola Politécnica. Universidade Federal do Rio de Janeiro. 2010.

PRAHALAD, C. K.; RAMASWAMY, V. Co-opting customer competence. Harvard Business Review, p. 79-87, jan./feb. 2000.

RAMASWAMY, V. e GOUILLART, F. The Power of Co-Creation, New York: Free Press. 2010.

RAMASWAMY, V. Co-creation of value: Toward an expanded paradigm of value creation. Marketing Review St. Gallen. 2009.

RYENGEN, Steffen. The Fuzzy Front End of Innovation: Hearing the Voice Of Customer on Credit Cards. Department of Strategy and Management. Norges Handelshøyskole. 2008.

SHAPIRO, B. P.; SVIOKLA, J. J. Mantendo Clientes. São Paulo: Makron Books, 1994. 